\title{
Virtual reality: A non-pharmacological complementary strategy facilitating Physical Therapy procedures for adolescent burned patients
}

Intsar S. Waked and Marwa M. Eid*

*Correspondence: alaaamr50@yahoo.com

CrossMark

$\leftarrow$ Click for updates

Physical Therapy Department for Surgery, Faculty of Physical Therapy, Cairo University, Giza, Egypt.

\begin{abstract}
Objective: the purpose of this study was to evaluate effectiveness of virtual reality (VR) in decreasing pain and facilitating physical therapy (PT) procedures for adolescent burned Patients.

Methods: A two-weeks randomized controlled study including fifty-six adolescent burned patients who randomly divided into two groups. VR group received VR during PT session while control group received PT without VR. Pain was assessed by adolescent pediatric pain tool (APPT) and ROM was assessed by goniometer at the end of each session.

Results: The results of study reported highly significant and substantial declines in all pain outcomes (mean total painful areas, pain intensity, sensory, affective, evaluative and temporal dimensions of pain) in VR group compared to control group, p value $\leq 0.001$. The percentage of decrement of pain intensity in VR group was $55.6 \%$ while for control group was $15.6 \%$. Regarding ROM measurement, for the first three sessions, the results of the study showed that there was no significant difference between both groups in mean ROM of hip extension, hip abduction, knee extension and ankle dorsiflexion, $\mathrm{p}$ value $>0.05$, however for the last three sessions, there was highly significant difference between both groups, $\mathrm{p}$ value $<0.05$. The percentage of improvement in ROM of Hip extension, hip abduction, dorsiflexion and knee extension in VR group were $14.2 \%, 85.2 \%, 26.1 \%$ and $82.2 \%$ respectively, while for control group the percentage of improvement were $8.3 \%, 24.7 \%, 11.8 \%$ and $24.1 \%$ respectively.

Conclusion: Based on the obtained results and previous studies results, our study concluded that virtual reality is powerful analgesic non-pharmacological adjunctive tool that helps in decreasing procedural pain during PT procedures. Its analgesic effects have beneficial effects on ROM of lower extremity of adolescent burned patients.
\end{abstract}

Keywords: Virtual Reality, Physical Therapy, Pain, Range of motion, Burn

\section{Introduction}

Physical therapy (PT) plays a vital role and it is necessary for rehabilitation of burned patients though painful sensation results during procedures of rehabilitation. Early and comprehensive PT helps in increasing range of motion (ROM) and prevents development of contractures secondary to burn or skin grafting. As a results PT rehabilitation is a key stone for improving functional outcomes, quality of life and minimizing post-burn complications [1].

Unfortunately, patients may be reverse to participate fully in PT procedures due to the significant procedural pain experiences that can be triggered by the manipulative activities that are intended to help them heal and function well [2]. Pain caused by the inflammatory response in and around the burn site as well as by acute intense procedural, pain caused by manipulation of the burned area that results in delay healing, poor physical and psychological health outcomes and prolonged hospitalization [3].

Opioid administration has been the standard pharmacologic and first choice treatment for managing rehabilitation related 
Waked et al, Physical Therapy and Rehabilitation 2019,

pain however they have many side effects including nausea, vomiting, itching, constipation, respiratory distress and risk of addiction. In adequate pain control with using opioid alone and their side-effects can limit their clinical use [4]. Therefore, burn care providers continue to search for non- pharmacologic tool for controlling pain. The rise and progress in technology has introduced new non-pharmacologic technology called Virtual Reality (VR) as a complementary interaction and impressive therapy used during treatment of burns. VR has been shown to be a useful non-pharmacologic adjunct by controlling intense procedural pain during burn care and rehabilitation [5].

The work of VR is to distract patient's attention away from painful procedures. VR technology is a favorable adjunctive pain management tool for adolescents, as demonstrated by some successful studies with pediatric and adults [6-8]. It was reported that VR decrease pain up to $50 \%$ [9]. Decreasing pain help in conducting PT procedures such as positioning, ROM exercises, and stretching exercises smoothly, thus preventing post burn contractures and functional limitations. Though clearly useful for inducing distraction in the management of significant acute rehabilitation-related pain for burn injuries, VR technology is not widely used in clinical settings, the purpose of this study was to introduce VR as an adjunctive tool and evaluate its effectiveness in decreasing pain and facilitating PT procedures for adolescent burned Patients.

\section{Materials and methods \\ Research design}

Two-weeks randomized controlled trial was conducted at Um Almasrieen General Hospital, Giza, Egypt. An informed consent was provided by all participants' relatives giving agreement to participation and publication for the study results. The study protocol was approved by Ethical committee, Faculty of Physical Therapy, Cairo University, Egypt.

\section{Inclusion \& Exclusion criteria}

Criteria for patients' inclusion were; (1) their age ranged from 11 17 years, (2) patients in acute stage, (3) Total Body Surface Area (TBSA) greater than 14\%, (4) Patients had deep second to third degree burn affecting lower extremity, patients able to subjectively evaluate his or her pain. Reasons for exclusion; (1) Patients with burns at any area that precluded with using VR apparatus (i.e. burn at ear, forehead), (2) patients with susceptibility to motion thickness, hearing or visual impairment and significant cognitive problems. (3) Patients with altered level of consciousness, organic brain disorder, seizure history, significant intellectual disability.

\section{Sampling and randomization}

Seventy-seven patients were checked according to eligibility criteria. One administration officer in burn unit was instructed to review the medical records and report all patients who fulfilled the inclusion criteria of the study (diagnosis, age,
TBSA, site) and had no exclusion criteria. Sixty-one patients out of seventy-seven fulfilled the inclusion criteria. Another administration officer was instructed for assigning the sixtyone patients into either VR or control group, random process included opening a sealed envelope prepared with random number generation by administration officer who was not involved in any part of the study. VR group; included thirtyone patients who underwent VR distraction technology during standard PT procedures which involved exercises in the form of positioning, active and active-assisted lower limb ROM exercises, 3 days/week for two weeks. Control group (C); included thirty patients received the standard PT only. All patients in both groups received the same medical care, Figure 1.

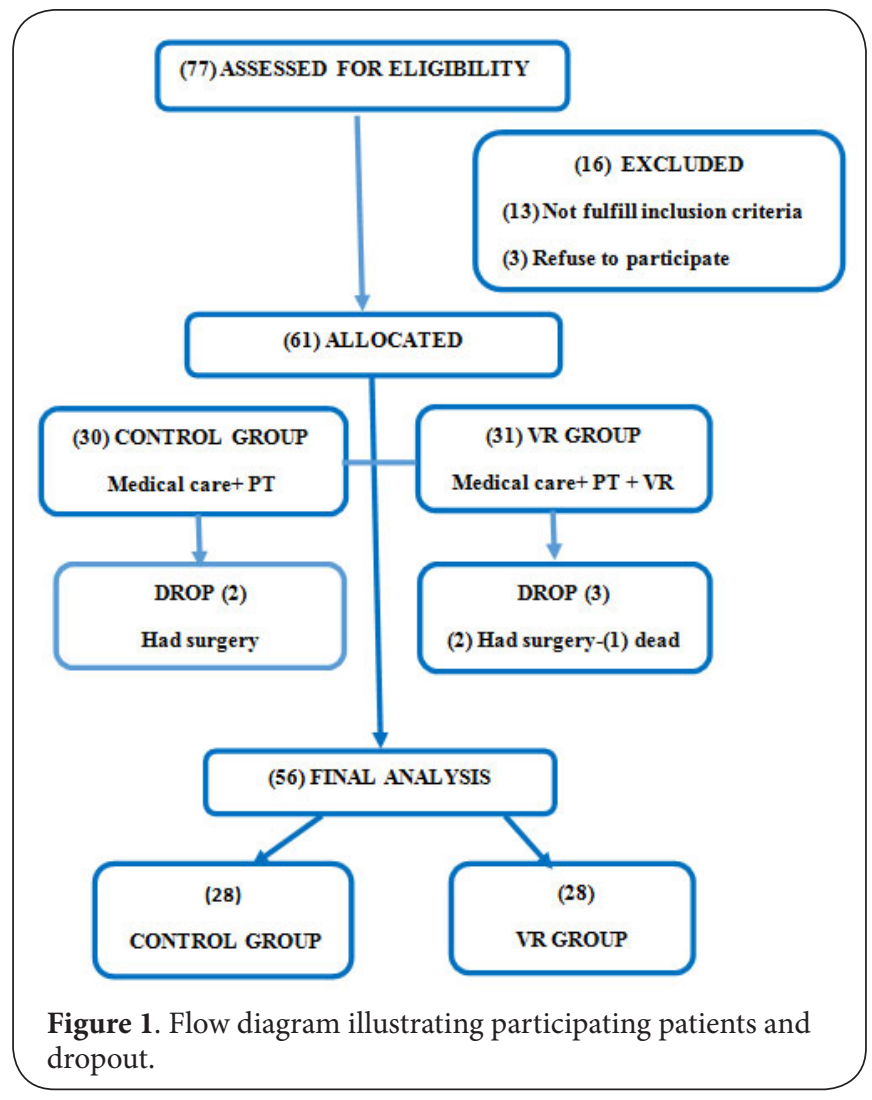

\section{Outcome measures}

\section{Evaluation of pain}

The Adolescent Pediatric Pain Tool (APPT) is a multi-dimensional pain tool used for self-assess pain by children and adolescents aged from 8 to 17 years. APPT is a one-page double sided paper consists of three main separate sections; (1) body outline diagram (BOD) that used to map the site of patient' pain, (2) word graphic rating scale (WGRS) which is a $10 \mathrm{~cm}$ visual analog scale used to assess pain intensity, with five graded descriptive words of pain intensity (no pain, mild, moderate, major and sever) 3) sixty-seven words descriptive list for pain quality to evaluate sensory; affective; evaluative; and 
temporal dimensions of pain. Many studies involving healthy and ill children with ages 8 to 18 established the validity and reliability of scale $[10,11]$.

The APPT was used for evaluation of pain immediately after each physical therapy session. The three sections of the APPT were scored separately [14]. 1) Total number of pain sites using the body diagram. 2) Pain intensity score by measuring distance in millimeters from the left end from word graphic scale to the patient mark. 3) Average of number of words describes pain quality for the four domains $[12,13]$.

\section{Range of Motion measurement (ROM)}

A standard goniometer was used for measuring lower limb ROM daily after each physical therapy session for two weeks for all patients in both groups. ROM measurements were done for hip abduction, extension, knee extension and ankle planter flexion.

\section{Intervention}

Virtual reality (VR) group received distraction via VR system that applied during physical therapy procedure. Participant chose which specific application; they would like to view from a document containing a screenshot for each application. Participants did not start VR experience until physical therapy session start. Physical therapy session included active free exercises, active assistant, stretching and positioning at the end of the session. Treatment duration was $30 \mathrm{~min}$, three days per week for two weeks. The treatment procedures (VR and PT) were explained to each patient to be familiarized. The Nurse began VR application while researcher conduct the physical therapy session, the nurse noted how long the patient played the VR and whether or not the patient wanted to change to different application. After each session had ended, the pain and ROM were assessed by the other researcher who blinded to patient's allocation.

\section{Apparatus}

An immersive, three-dimensional, interactive simulated environment was created using 3D VR Headset 3D Glasses VR BOX for iPhone 65 Samsung 3D movie video games with packaged high quality. The participant chose one of ten VR applications. To create VR experience, the iPod was placed inside of VR headset. Patient also was given the option to listen to the sound headphone VR application on.

\section{Statistical analysis}

Pain was assessed using APPT scale immediately after each session for six sessions for all patients in both groups. There are three components in APPT scale and each component was statistically analyzed separately. Also ROM was assessed for hip extension, hip abduction, knee extension, ankle dorsiflexion immediately after each session for all patients in both groups. Shapiro-wilk test was used to detect normal distribution of data. Repeated measures ANOVA test was used to test the improvement in pain and ROM within each group for six sessions. Independent t-test was used to assess changes in pain and ROM between both groups. Continuous data was displayed as mean and standard deviation while categorical data as number and percentage. A significant level was considered when $p$ value $\leq 0.05$.

\section{Results}

Figure 1 represented flow diagram that illustrated the participated patients and dropout through the study. 56 patients were available for final analysis, 28 patients for each group. The findings of the study were displayed under the following titles. 1.Patient demographic data

2.Pain measurements

3.Range of motion measurements

\section{Patient demographic data}

Demographic characteristics of all patients of both groups were compared at baseline and showed similarities. There were no significant differences between both groups regarding age, sex, depth. TBSA, p value $>0.05$, Table 1 .

Table 1. Patients demographic data.

\begin{tabular}{llll}
\hline Variable & VR group & Control group & P-value \\
\hline Age & $13.96 \pm 2.05$ & $13.61 \pm 1.97$ & $0.508^{*}$ \\
TBSA & $25.79 \pm 6.01$ & $27.50 \pm 6.46$ & $0.308^{*}$ \\
\hline Depth & & & \\
- SPT & $4(14.3 \%)$ & $7(25 \%)$ & -- \\
- DPT & $6(21.4 \%)$ & $6(21.4 \%)$ & $0.418^{*}$ \\
- FT & $2(7.2 \%)$ & $1(3.6 \%)$ & -- \\
- Mixed & $16(57.1 \%)$ & $14(50.0 \%)$ & -- \\
\hline Sex & & \\
- Male & $18(64.3 \%)$ & $13(46.4 \%)$ & $0.183^{*}$ \\
- Female & $10(35.7 \%)$ & $15(53.6 \%)$ & -- \\
\hline Data as mean \pm SD; SPT: superficial partial \\
thickness, DPT; Deep partial thickness, \\
FT; Full thickness, ${ }^{*}$ no significant difference
\end{tabular}

\section{Pain measurements}

Statistical analysis of total number of painful body area after each session

The findings of study showed marked decline in the mean total number of painful body areas in VR group with the time from first session to sixth session, $F(1.90,51.3)=46.81, p<0.001$. For control group, there is decrease in the mean total number of painful body areas from first session to sixth session, $\mathrm{F}$ (1.48, $40)=27.83$, p value $<0.05$. In comparing both groups, there was highly significant difference between both groups. The percentage of decrement in mean total number of painful body areas in VR group and control group were $31.5 \%$ and 18\% respectively, Table 2.

\section{Measurement of pain intensity}

The results of study showed marked decrease in pain intensity 
Waked et al, Physical Therapy and Rehabilitation 2019,

in VR group with the time from first session to sixth session, $F(3.05,82.29)=296.39, p<0.001$. For control group, there is decrease in pain intensity from first session to sixth session, $F$ $(39.36,41.31)=25.724$, $p$ value $<0.05$. In comparing both groups, there was highly significant difference between both groups. The percentage of decrement of pain intensity in VR group and control group were $55.6 \%$ and $15.6 \%$ respectively, Table 3 .

Table 2. Statistical analysis of total number of painful areas.

\begin{tabular}{llll}
\hline Variable & VR group & Control group & P-value \\
\hline $1^{\text {st }}$ session & $10.04 \pm 2.56$ & $11.42 \pm 3.05$ & $0.007^{\star}$ \\
$2^{\text {nd }}$ session & $8.96 \pm 2.28$ & $11.11 \pm 2.83$ & $0.003^{*}$ \\
$3^{\text {rd }}$ session & $8.53 \pm 2.08$ & $10.64 \pm 2.57$ & $0.001 \dagger$ \\
$4^{\text {th }}$ session & $8.10 \pm 2.07$ & $10.25 \pm 2.44$ & $0.001 \dagger$ \\
$5^{\text {th }}$ session & $7.67 \pm 1.87$ & $9.78 \pm 2.25$ & $0.000 \dagger$ \\
$6^{\text {th }}$ session & $6.85 \pm 2.79$ & $9.36 \pm 2.00$ & $0.000 \dagger$ \\
\hline
\end{tabular}

Data as mean $\pm S D,{ }^{*}$ p value $<0.05, \quad \dagger p$ value $<0.001$

Table 3. Statistical analysis of pain intensity.

\begin{tabular}{llll}
\hline Variable & VR group & Control group & P-value \\
\hline $1^{\text {st }}$ session & $8.68 \pm 0.90$ & $9.14 \pm 0.76$ & $0.042^{*}$ \\
$2^{\text {nd }}$ session & $7.82 \pm 0.86$ & $8.32 \pm 0.77$ & $0.026^{*}$ \\
$3^{\text {rd }}$ session & $6.92 \pm 0.98$ & $7.92 \pm 0.86$ & $0.000 \dagger$ \\
$4^{\text {th }}$ session & $5.86 \pm 1.00$ & $7.89 \pm 0.83$ & $0.000 \dagger$ \\
$5^{\text {th }}$ session & $4.86 \pm 1.00$ & $7.85 \pm 0.85$ & $0.000 \dagger$ \\
$6^{\text {th }}$ session & $3.85 \pm 1.04$ & $7.71 \pm 0.89$ & $0.000 \dagger$ \\
\hline
\end{tabular}

Data as mean $\pm S D,{ }^{*} \mathrm{p}$ value $<0.05, \quad \dagger \mathrm{p}$ value $<0.001$

\section{Pain quality dimensions}

The results of study showed marked decrease in mean total number of descriptive words of sensory $F(1.79,48.52)=259.32$, $p<0.001$, affective $F(1.37,75.66)=122.72, p<0.001$, evaluative $F(2.22,59.92)=219.51, p<0.001$, and temporal dimensions $F(2.52,68.29)=414.88, p<0.001$ in VR group with the time from first session to sixth session. For control group, there is decrease mean total number of descriptive words of sensory $F(1.29,35.02)=13.76, p<0.001$, affective $F(2.91,78.49)=41.27$, $p<0.001$, evaluative $F(3.06,82.56)=21.15 p<0.001$ and temporal dimension $F(3.02,81.63)=42.57, p<0.001$ with the time from first session to sixth session.

In comparing both groups, there was highly significant difference between both groups. The percentage of decrement in mean total number of descriptive words of sensory, affective, evaluative and temporal dimension were $45.5 \%$, $68.9 \%, 60.3 \%$ and $58.3 \%$ respectively for VR group while for control group the percentage of improvement were $10.8 \%$ and $19.7 \%, 12.1 \%$ and $17.7 \%$ respectively, Table 4 .

\section{ROM measurements}

The results of study showed marked increase in ROM of hip extension, $F(1.42,38.34)=20.23$, $p<0.001$, hip abduction, $F(2.89$, $78.17)=562.09, p<0.001$, knee extension, $F(1.96,53.06)=86.47$, $p<0.001$ and dorsiflexion, $F(2.17,58.68)=440.55, p<0.001$ in VR group with the time from first session to sixth session. For control group, there is increase in ROM of hip extension, $\mathrm{F}$ $(1.03,27.86)=7, p<0.001$, hip abduction, $F(1.45,39.19)=92.62$, $p<0.001$, knee extension, $F(2.29,61.84)=258.06, p<0.001$,

Table 4. Statistical analysis of pain quality dimensions.

\begin{tabular}{lllllll}
\hline \multirow{2}{*}{ Variable } & \multicolumn{4}{l}{ Sensory dimension } & \multicolumn{4}{l}{ Affective dimension } \\
\cline { 2 - 7 } & VR & Control & P-value & VR & Control & P-value \\
\hline $1^{\text {st }}$ session & $21.93 \pm 4.55$ & $24.46 \pm 4.28$ & $0.036^{*}$ & $9.43 \pm 0.96$ & $9.96 \pm 0.96$ & $0.042^{*}$ \\
$2^{\text {nd }}$ session & $19.96 \pm 4.27$ & $22.79 \pm 5.47$ & $0.037^{\star}$ & $7.68 \pm 0.90$ & $9.14 \pm 0.89$ & $0.000 \dagger$ \\
$3^{\text {rd }}$ session & $18.25 \pm 4.07$ & $22.61 \pm 5.40$ & $0.001 \dagger$ & $6.21 \pm 0.99$ & $8.82 \pm 0.86$ & $0.000 \dagger$ \\
$4^{\text {th }}$ session & $15.96 \pm 3.92$ & $22.46 \pm 5.37$ & $0.000 \dagger$ & $4.93 \pm 1.01$ & $8.64 \pm 0.83$ & $0.000 \dagger$ \\
$5^{\text {th }}$ session & $13.89 \pm 3.71$ & $22.14 \pm 5.20$ & $0.000 \dagger$ & $4.00 \pm 0.94$ & $8.36 \pm 0.62$ & $0.000 \dagger$ \\
$6^{\text {th }}$ session & $11.96 \pm 3.98$ & $21.82 \pm 5.08$ & $0.000 \dagger$ & $2.93 \pm 0.94$ & $8.00 \pm 0.86$ & $0.000 \dagger$ \\
\hline & Evaluative dimension & & Temporal dimension & \\
\cline { 2 - 7 } & VR & Control & P-value & VR & Control & P-value \\
\hline $1^{\text {st }}$ session & $7.11 \pm 1.07$ & $7.60 \pm 0.57$ & $0.033^{*}$ & $9.11 \pm 0.88$ & $9.71 \pm 1.01$ & $0.020^{*}$ \\
$2^{\text {nd }}$ session & $6.25 \pm 0.89$ & $7.25 \pm 0.75$ & $0.000 \dagger$ & $8.89 \pm 0.74$ & $9.39 \pm 0.79$ & $0.017^{\star}$ \\
$3^{\text {rd }}$ session & $5.36 \pm 0.68$ & $7.18 \pm 0.72$ & $0.000 \dagger$ & $8.04 \pm 0.58$ & $9.14 \pm 0.54$ & $0.000 \dagger$ \\
$4^{\text {th }}$ session & $4.50 \pm 0.50$ & $7.07 \pm 0.66$ & $0.000 \dagger$ & $7.00 \pm 0.54$ & $8.79 \pm 0.49$ & $0.000 \dagger$ \\
$5^{\text {th }}$ session & $3.68 \pm 0.48$ & $6.86 \pm 0.71$ & $0.000 \dagger$ & $6.00 \pm 0.60$ & $8.00 \pm 0.60$ & $0.000 \dagger$ \\
$6^{\text {th }}$ session & $2.82 \pm 0.48$ & $6.68 \pm 0.55$ & $0.000 \dagger$ & $3.79 \pm 0.74$ & $7.96 \pm 0.64$ & $0.000 \dagger$ \\
\hline
\end{tabular}

Data as mean $\pm \mathrm{SD}, \quad{ }^{*}$ p value $<0.05, \quad \dagger \mathrm{p}$ value $<0.001$ 
dorsiflexion, $F(2.10,56.78)=191.2, p<0.001$ with the time from first session to sixth session.

In comparing both groups, there was no significant difference between both groups in mean ROM of hip extension, hip abduction, knee extension and ankle dorsiflexion in the first week 'sessions $p$ value $>0.05$, however there was highly significant difference between both groups in the second week 'sessions, $p$ value $<0.05$. The percentage of improvement in ROM of Hip extension, hip abduction, dorsiflexion and knee extension in VR group were 14.2\%, 85.2\%, 26.1\% and $82.2 \%$ respectively, while for control group the percentage of improvement were $8.3 \%, 24.7 \%, 11.8 \%$ and $24.1 \%$ respectively Table 5 .

\section{Discussion}

One of the most important challenges of living with persistent pain, is pain appeared whenever the body part is moved. The increment in pain make the patient unwilling to participate in motion and fearful of daily activities such as transferring and walking. Pain is a problem that has significant impact on patient's participation in rehabilitation therapy. Although PT is vital and essential part for rehabilitation of burned patients, patients refused to participate in physical therapy program in order to avoid pain, as consequences [15,4].

Many non-pharmacological therapies used as powerful adjunctive to pharmacological agents for decreasing pain in patients underwent physical procedures such as relaxation and stress reduction therapy, biofeedback, hypnosis and distraction therapy. Through last decade distraction therapy is growing to be used and is delivered through VR with using protective goggles and earphone to enhance visual and auditory stimulation [16-18].
Psychologically based virtual reality programs can either be relaxation or distraction in type [18]. Our study used VR distraction therapy to evaluate its effectiveness in relieving pain and increasing ROM over two weeks of treatment for inpatient burned adolescent undergoing physiotherapy. Pain and LL ROM outcomes were measured immediately after each PT session for 6 sessions, day per day for both VR and control groups.

The results of study reported highly significant and substantial declines in all pain outcomes (mean total painful areas, pain intensity, sensory, affective, evaluative and temporal dimensions of pain) in VR group compared to control group, $p$ value $\leq 0.001$. The results of this study provides evidence that user interaction in a virtual environment can be a useful adjunct to pharmacologic analgesia in helping to control acute, procedural, rehabilitation related pain in burn patients.

A reduction in pain severity of $30 \%$ or more is considered to be clinically meaningful by patients [19]. The percentage of decrement of pain intensity in VR group was $55.6 \%$ while for control group was $15.6 \%$.

Findings of this study were in agreement with the findings of previous studies suggested that immersive VR has a significant analgesic effect in post-burn wound care as well as rehabilitation settings [18,20-24]. However only one study at all [25] showed significant negative effects on pain. Authors of the study reported the effects might be attributable to the statistical analysis that results from pre-existing differences in pain between both intervention and control group that were not considered.

These findings are not surprising considering a review of the literature on the effects of VR burned patients during physiotherapy procedures that showed similar findings but

Table 5. Statistical analysis of ROM measurements.

\begin{tabular}{lllllll}
\hline \multirow{2}{*}{ Variable } & Hip extension & \multicolumn{5}{l}{ Hip abduction } \\
\cline { 2 - 7 } & VR & Control & P-value & VR & Control & P-value \\
\hline $1^{\text {st }}$ session & $96.18 \pm 9.49$ & $94.04 \pm 8.07$ & $0.367^{*}$ & $17.32 \pm 2.96$ & $17.60 \pm 3.06$ & $0.724^{*}$ \\
$2^{\text {nd }}$ session & $97.54 \pm 8.56$ & $97.29 \pm 9.87$ & $0.920^{*}$ & $19.60 \pm 3.92$ & $17.86 \pm 3.01$ & $0.067^{*}$ \\
$3^{\text {rd }}$ session & $103.36 \pm 9.05$ & $98.25 \pm 9.53$ & $0.058^{*}$ & $21.03 \pm 3.69$ & $18.79 \pm 3.33$ & $0.020 \dagger$ \\
$4^{\text {th }}$ session & $104.04 \pm 8.44$ & $99.36 \pm 9.61$ & $0.045 \dagger$ & $25.39 \pm 2.81$ & $19.82 \pm 3.35$ & $0.000 \dagger$ \\
$5^{\text {th }}$ session & $106.71 \pm 9.20$ & $100.82 \pm 9.52$ & $0.022 \dagger$ & $28.89 \pm 3.10$ & $20.86 \pm 3.22$ & $0.000 \dagger$ \\
$6^{\text {th }}$ session & $109.89 \pm 9.43$ & $101.89 \pm 9.52$ & $0.003 \dagger$ & $32.07 \pm 3.07$ & $21.96 \pm 3.29$ & $0.000 \dagger$ \\
\hline & Knee extension & & & Ankle dorsiflexion & \\
\cline { 2 - 7 } & VR & Control & P-value & VR & Control & P-value \\
\hline $1^{\text {st }}$ session & $99.54 \pm 14.46$ & $98.75 \pm 12.52$ & $0.829^{*}$ & $12.64 \pm 3.87$ & $13.21 \pm 3.20$ & $0.550^{*}$ \\
$2^{\text {nd }}$ session & $100.64 \pm 10.71$ & $101.18 \pm 12.98$ & $0.867^{*}$ & $13.93 \pm 3.69$ & $13.46 \pm 3.07$ & $0.611^{*}$ \\
$3^{\text {rd }}$ session & $108.39 \pm 9.79$ & $103.39 \pm 13.11$ & $0.112^{*}$ & $15.25 \pm 3.48$ & $13.64 \pm 3.03$ & $0.071^{*}$ \\
$4^{\text {th }}$ session & $116.54 \pm 8.23$ & $104.93 \pm 13.07$ & $0.000 \dagger$ & $16.89 \pm 3.26$ & $14.25 \pm 2.84$ & $0.002 \dagger$ \\
$5^{\text {th }}$ session & $121.39 \pm 7.90$ & $108.04 \pm 12.88$ & $0.000 \dagger$ & $20.04 \pm 0.60$ & $15.39 \pm 2.77$ & $0.000 \dagger$ \\
$6^{\text {th }}$ session & $125.54 \pm 7.10$ & $110.39 \pm 12.60$ & $0.000 \dagger$ & $23.03 \pm 3.74$ & $16.39 \pm 2.77$ & $0.000 \dagger$ \\
\hline
\end{tabular}

Data as mean $\pm \mathrm{SD}, \quad{ }^{\star} \mathrm{p}$ value $>0.05, \quad \dagger \mathrm{p}$ value $<0.05$ 
Waked et al, Physical Therapy and Rehabilitation 2019,

these previous studies did not examine between groups effects after repeated use of VR during PT procedures. Thus the current findings contribute to the literature by providing preliminary evidence for using VR distraction as adjunct tool helps to decrease pain with burned adolescent undergoing physical therapy.

The application of VR distraction depends on the assumption that the experience of pain is largely cognitively controlled. Regards gate-control theory [26], an incoming neural signal is interpreted as more or less painful depends on where patients focus their attention at this time. VR distraction draws a significant amount of attention into another world away from the painful stimulus, leaving less attention available to process pain signals [27].

The results of the study showed that there was no significant difference between both groups in mean ROM of hip extension, hip abduction, knee extension and ankle dorsiflexion in the first three sessions, $p$ value $>0.05$, however there was highly significant difference between both groups starting from the fourth session, $p$ value $<0.05$. The percentage of improvement in ROM of Hip extension, hip abduction, dorsiflexion and knee extension in VR group were $14.2 \%, 85.2 \%, 26.1 \%$ and $82.2 \%$ respectively, while for control group the percentage of improvement were $8.3 \%, 24.7 \%, 11.8 \%$ and $24.1 \%$ respectively.

Reducing patient pain leads to decrease patient distress that could reduce avoidance behavior and make the patient more cooperative and increased willingness to participate during physical therapy procedures, and therefore better long-term outcomes. Such as better range of motion post-discharge, shorter hospital stays, and reduced incidence of chronic pain.

A randomized, controlled, within-subjects study examined the effects of VR as an adjunctive analgesic technique for hosptalized pediatric burn in patients undergoing painful PT. The results of study showed that the maximum ROM was not different between treatment conditions, but was significantly greater after the second treatment condition [4].

One of the strength point of our study is the assessment of pain, due to multidimensional nature of pain, we used APPT for multidimensional assessment of all pain outcomes, pain intensity, sensory, affective, evaluative and temporal dimensions. Limitation of our study related to the nature of distraction as there was inability to achieve blinding of participating physical therapists.

\section{Conclusion}

Based on the obtained results and previous studies results, our study concluded that virtual reality is powerful analgesic non-pharmacological adjunctive tool that helps in decreasing procedural pain during physical therapy procedures. Its analgesic effects have beneficial effects on ROM of lower extremity of adolescent burned patients.

\section{Competing interests}

The authors declare that they have no competing interests.

Authors' contributions
\begin{tabular}{|l|c|c|}
\hline Authors' contributions & ISW & MME \\
\hline Research concept and design & $\checkmark$ & $\checkmark$ \\
\hline Collection and/or assembly of data & -- & $\checkmark$ \\
\hline Data analysis and interpretation & $\checkmark$ & -- \\
\hline Writing the article & $\checkmark$ & $\checkmark$ \\
\hline Critical revision of the article & $\checkmark$ & $\checkmark$ \\
\hline Final approval of article & $\checkmark$ & $\checkmark$ \\
\hline statistical analysis & $\checkmark$ & -- \\
\hline
\end{tabular}

\section{Acknowledgment}

The authors express their thanks to all patients for their confidence and collaboration that make this study possible. Also, the authors declare no conflict of interest or funding for this research.

Publication history

Editor: Mohammad H. Hadadzadeh, wheeling Jesuit University, USA. Received: 29-Aug-2018 Final Revised: 30-Sept-2018

Accepted: 02-Oct-2018 Published: 05-Jan-2019

\section{References}

1. Esselman PC, Thombs BD, Magyar-Russell G and Fauerbach JA. Burn rehabilitation: state of the science. Am J Phys Med Rehabil. 2006; 85:383-413. | Article | PubMed

2. Patterson DR, Sharar SR. Burn pain. In: Loeser JD, Butler SH, Chapman CR and Turk DC. Bonica's management of pain. Philadelphia, PA: Lippincott. 2001.

3. van der Heijden MJE, de Jong A, Rode H, Martinez R and van Dijk M. Assessing and addressing the problem of pain and distress during wound care procedures in paediatric patients with burns. Burns. 2018; 44:175-182. | Article | PubMed

4. Schmitt YS, Hoffman HG, Blough DK, Patterson DR, Jensen MP, Soltani M, Carrougher GJ, Nakamura D and Sharar SR. A randomized, controlled trial of immersive virtual reality analgesia, during physical therapy for pediatric burns. Burns. 2011; 37:61-8. | Article | PubMed Abstract | PubMed FullText

5. Uman LS, Birnie KA, Noel M, Parker JA, Chambers CT, McGrath PJ and Kisely SR. Psychological interventions for needle-related procedural pain and distress in children and adolescents. Cochrane Database Syst Rev. 2013; CD005179. | Article | PubMed

6. Miller K, Rodger S, Bucolo S, Greer R and Kimble RM. Multi-modal distraction. Using technology to combat pain in young children with burn injuries. Burns. 2010; 36:647-58. | Article | PubMed

7. Das DA, Grimmer KA, Sparnon AL, McRae SE and Thomas BH. The efficacy of playing a virtual reality game in modulating pain for children with acute burn injuries: a randomized controlled trial [ISRCTN87413556]. BMC Pediatr. 2005; 5:1. | Article | PubMed Abstract I PubMed FullText

8. Morris LD, Louw QA and Grimmer-Somers K. The effectiveness of virtual reality on reducing pain and anxiety in burn injury patients: a systematic review. Clin J Pain. 2009; 25:815-26. | Article | PubMed

9. Markus LA, Willems KE, Maruna CC, Schmitz CL, Pellino TA, Wish JR, Faucher LD and Schurr MJ. Virtual reality: feasibility of implementation in a regional burn center. Burns. 2009; 35:967-9. | Article | PubMed

10. Savedra MC, Tesler MD and Holzemer WL. Adolescent pediatric pain tool (APPT) preliminary user's manual. San Francisco: University of California. 1989.

11. Wilkie DJ, Holzemer WL, Tesler MD, Ward JA, Paul SM and Savedra MC. Measuring pain quality: validity and reliability of children's and adolescents' pain language. Pain. 1990; 41:151-9. | Article | PubMed

12. Tesler MD, Savedra MC, Holzemer WL, Wilkie DJ, Ward JA and Paul 
Waked et al, Physical Therapy and Rehabilitation 2019,

http://www.hoajonline.com/journals/pdf/2055-2386-6-1.pdf

SM. The word-graphic rating scale as a measure of children's and adolescents' pain intensity. Res Nurs Health. 1991; 14:361-71. | PubMed

13. Savedra MC, Holzemer WL, Tesler MD and Wilkie DJ. Assessment of postoperation pain in children and adolescents using the adolescent pediatric pain tool. Nurs Res. 1993; 42:5-9. I PubMed

14. Fernandes AM, De Campos C, Batalha L, Perdigao A and Jacob E. Pain assessment using the adolescent pediatric pain tool: a systematic review. Pain Res Manag. 2014; 19:212-8. | PubMed Abstract | PubMed FullText

15. Vlaeyen JW and Crombez G. Fear of movement/(re)injury, avoidance and pain disability in chronic low back pain patients. Man Ther. 1999; 4:187-95. | Article | PubMed

16. Hoffman HG. Virtual-reality therapy. Sci Am. 2004; 291:58-65. I PubMed

17. Hoffman HG, Patterson DR, Carrougher GJ and Sharar SR. Effectiveness of virtual reality-based pain control with multiple treatments. Clin J Pain. 2001; 17:229-35. | Article | PubMed

18. Hoffman HG, Patterson DR, Magula J, Carrougher GJ, Zeltzer K, Dagadakis $\mathrm{S}$ and Sharar SR. Water-friendly virtual reality pain control during wound care. J Clin Psychol. 2004; 60:189-95. | Article | PubMed

19. Farrar JT, Portenoy RK, Berlin JA, Kinman JL and Strom BL. Defining the clinically important difference in pain outcome measures. Pain. 2000; 88:287-94. | Article | PubMed

20. Hoffman HG, Doctor JN, Patterson DR, Carrougher GJ and Furness TA, 3rd. Virtual reality as an adjunctive pain control during burn wound care in adolescent patients. Pain. 2000; 85:305-9. | Article | PubMed

21. Hoffman HG, Garcia-Palacios A, Patterson DR, Jensen M, Furness T, 3rd and Ammons WF, Jr. The effectiveness of virtual reality for dental pain control: a case study. Cyberpsychol Behav. 2001; 4:527-35. | Article | PubMed

22. Wright JL, Hoffman HG and Sweet RM. Virtual reality as an adjunctive pain control during transurethral microwave thermotherapy. Urology. 2005; 66:1320. | Article | PubMed

23. Steele E, Grimmer K, Thomas B, Mulley B, Fulton I and Hoffman H. Virtual reality as a pediatric pain modulation technique: a case study. Cyberpsychol Behav. 2003; 6:633-8. | Article I PubMed

24. Das DA, Grimmer KA, Sparnon AL, McRae SE and Thomas BH. The efficacy of playing a virtual reality game in modulating pain for children with acute burn injuries: a randomized controlled trial [ISRCTN87413556]. BMC Pediatr. 2005; 5:1. I Article I PubMed Abstract I PubMed FullText

25. Konstantatos AH, Angliss M, Costello V, Cleland H and Stafrace S. Predicting the effectiveness of virtual reality relaxation on pain and anxiety when added to PCA morphine in patients having burns dressings changes. Burns. 2009; 35:491-9. | Article | PubMed

26. Hoffman HG, Patterson DR and Carrougher GJ. Use of virtual reality for adjunctive treatment of adult burn pain during physical therapy: a controlled study. Clin J Pain. 2000; 16:244-50. | Article I PubMed

27. Melzack R and Wall PD. Pain mechanisms: a new theory. Science. 1965; 150:971-9. | Article | PubMed

\section{Citation:}

Waked IS and Eid MM. Virtual reality: A nonpharmacological complementary strategy facilitating Physical Therapy procedures for adolescent burned patients. Phys Ther Rehabil. 2019; 6:1.

http://dx.doi.org/10.7243/2055-2386-6-1 